Journal of Social Sciences 5 (4): 423-430, 2009

ISSN 1549-3652

(C) 2009 Science Publications

\title{
The Effects of Absorptive Capacity and Recipient Collaborativeness as Technology Recipient Characteristics on Degree of Inter-Firm Technology Transfer
}

\author{
A.W. Sazali, C.R. Raduan, U. Jegak and A. Haslinda \\ Graduate School of Management, University Putra Malaysia, 43400 Selangor, Malaysia
}

\begin{abstract}
Problem statement: As an efficient means to increase global competitiveness, technological capabilities and potential for local innovation, organizations in the developing countries are working hard to collaborate, learn and internalize their foreign partner's technological knowledge by forming strategic alliances or International Joint Ventures (IJVs). Technology recipient characteristics, as one of the important actors/facilitators of inter-firm technology transfer, have increasingly become crucial factors in determining the success or failure of inter-firm technology transfer within IJVs. Since the current issue on inter-firm Technology Transfer (TT) in the developing countries is centered on the efficiency and effectiveness of the transfer process by the Multinationals (MNCs) therefore the success is often associated with or measured by degree of technology transferred to local partners. Based on the underlying knowledge-based view and organizational learning perspective, this study aims to empirically examine the effects of two critical elements of technology recipient characteristics: Absorptive Capacity (ACAP) and Recipient Collaborativeness (RCOL) on degree of technology transfer: Degree of tacit and explicit knowledge in IJVs. Approach: Using the quantitative analytical approach, the theoretical model and hypotheses in this study were tested based on empirical data gathered from 128 joint venture companies registered with the Registrar of Companies Of Malaysia (ROC). Data obtained from the survey questionnaires were analyzed using the correlation coefficients and multiple linear regression analyses. Results: The results revealed that recipient collaborativeness as the critical element of technology recipient characteristics has strong significant effects on both degrees of tacit and explicit knowledge. Although absorptive capacity has been strongly emphasized of its significance effect, however, the results are not statistically significant. Conclusion/Recommendations: The study had bridged the literature gaps in such that it provides empirical evidence on the effects of two generic technology recipient attributes: absorptive capacity and recipient collaborativeness on degree of inter-firm technology transfer: degree of tacit and explicit knowledge.
\end{abstract}

Key words: Inter-firm technology transfer, international joint ventures, absorptive capacity, recipient collaborativeness, Malaysia

\section{INTRODUCTION}

Studies from Knowledge-Based View (KBV) perspective have acknowledged that MNCs tend to be more protective of their advance technology, knowledge and competencies embodied in products, processes and management because these strategic valuable resources and competencies are their main sources of competitive advantage ${ }^{[2,22,23]}$. On the other hand, Organizational Learning (OL) perspective studies have suggested that technology and knowledge tend to be protected by the supplier when the recipients are opportunistic in the collaborative relationship ${ }^{[12]}$. Thus, in the context of inter-firm Technology Transfer (TT) through International Joint Ventures (IJVs), the remaining question is on the extent of TT by foreign MNCs, especially when transferring their advance technology to local recipient partner. While realizing that technologies, knowledge and competencies are the supplier's main source of competitive advantage, the current TT issue in IJVs revolves around the extent of degree of technologies that are being transferred by the suppliers to recipient partners in terms of tacit knowledge (new product/service development, managerial systems and practice, process designs and new marketing expertise) and explicit knowledge (manufacturing/service techniques/skills, promotion techniques/skills, distribution know-how and purchasing know-how ${ }^{[17]}$. This is because from the recipient's perspective, TT success is not merely

Corresponding Author: A.W. Sazali, Graduate School of Management, University Putra Malaysia, 43400 Selangor, Malaysia 
possessing the ability to operate, maintain or repair the machineries at the production level (transmission) but it also includes the ability to learn, acquire, absorb and apply new external technologies and knowledge embedded in product materials, physical assets, processes and production and management capabilities (absorption) ${ }^{[6]}$.

Previous studies on intra-firm knowledge transfer have acknowledged the significant influence of technology actors and facilitators/barriers such as the characteristics of knowledge transferred, source, recipient and contextual/relational in the knowledge transfer process ${ }^{[9,28,29]}$. Thus, in the context of inter-firm TT where technology transfer processes are more complex, difficult, involve the process of transferring technology across organizational boundary to unaffiliated firms and complex relationship, the impending issue now is on the extent of effects of TT Characteristics (TTCHARS) in determining the degree or level of Technology Transfer (TTDEG). Specifically to what extents do TT characteristics influenced TTDEG? This study attempts to address the above issue in particular the effects of two critical elements of Technology Recipient Characteristics (TRCHAR): Absorptive Capacity (ACAP) and Recipient Collaborativeness (RCOL) on degree of inter-firm Technology Transfer (TTDEG): Degree of Tacit (TCTDEG) and Explicit knowledge (EXPDEG) in IJVs.

Technology recipient characteristics and degree of inter-firm technology transfer: The Technology Recipient Characteristics (TRCHAR) have been affirmed by many studies as the important factors that affect Knowledge Transfer (KT). Among the recipient characteristics that have been identified by literature to influence TT and Knowledge Transfer (KT) are absorptive capacity ${ }^{[5,9,10,25,15,16,19]}$, experience ${ }^{[43,44]}$, prior knowledge and experience ${ }^{[11,30]}$, knowledge relatedness $^{[11]}$, learning capacity ${ }^{[18]}$, receptivity ${ }^{[3]}$, learning intent or objectives ${ }^{[3,4,10,12,26]}$, managerial belief rigidity $^{[13]}$ and recipient collaborativeness, readiness and method comprehensiveness ${ }^{[32]}$. This study attempts to bridge the gaps in literature by examining two critical elements of TRCHAR: Absorptive Capacity (ACAP) and Recipient Collaborativeness (RCOL) and their effects on degree of inter-firm technology transfer (TTDEG) based on the underlying KBV and OL perspectives. From past theoretical and empirical studies, ACAP and RCOL are expected to have a significant positive impact on TTDEG.

\section{Theory and hypotheses:}

Absorptive capacity and degree of technology transfer: As TT involves the process of transmission and absorption of knowledge ${ }^{[6]}$, the recipient firm's ability to absorb the knowledge transferred depends on the degree of their Absorptive Capacity (ACAP). Past studies have shown that a low degree of technology recipient's ACAP impedes both intra and inter-firm $\mathrm{KT}^{[5,9,10,25,15,16,27]}$. The concept of ACAP has been extensively reviewed in both theoretical and empirical studies. In their seminal paper, Cohen and Levinthal ${ }^{[5]}$ define ACAP as "the firm's ability to recognize the value of new external information, assimilate it and apply it to commercial ends". ACAP of a firm is primarily a function of the recipient firm's level of prior related knowledge. Prior related knowledge is closely related to the individuals units of knowledge available within the organizations. The accumulation of prior knowledge increases the ability to make sense of, assimilate and use new knowledge ${ }^{[23]}$. The firm's ACAP tends to be developed cumulatively in which ACAP is more likely to be developed and maintained as a byproduct of routine activity when the knowledge domain that the firm wishes to exploit is closely related to its current knowledge base ${ }^{[5]}$. Prior related knowledge, which includes basic/minimal skills, a shared language, positive attitude towards learning, relevant prior experience and up-to-date information on knowledge domain, is critical for an organization to assimilate and exploit new knowledge ${ }^{[5,28,29]}$. By possessing sufficient prior related knowledge, which is closely associated with new knowledge, the organization will have adequate ability to absorb new technological and innovative competencies and capabilities ${ }^{[5]}$.

A stream of strategic alliance literatures has dealt with the concept of $\mathrm{ACAP}^{[10,11,27,29]}$. Hamel ${ }^{[14]}$ applies the term "receptivity" to have similar notion to ACAP in explaining the organization's capacity to learn from their partner. Several factors have been identified as determinants of receptivity: (1) the appropriateness of resource deployment, (2) incentive systems, (3) attitudes towards learning and (4) the propensity to unlearn $^{[10]}$. In a similar vein, few researchers have expended the concept of receptivity to include "local parent receptivity" which refers to the readiness and ability of local parent to appreciate and receive the knowledge brought in by the foreign parent ${ }^{[13,31]}$. All partners are not equally adept at learning because the capacity to learn in strategic alliance mainly depends on the degree of receptivity of the partners. Inter-partner learning is determined by: (1) the sense of confidence which relates to partners' learning attitudes and the need to unlearn, (2) the degree of skills' gap with the industry leaders, (3) the absorptiveness of the receptors i.e., the ability to observe, interpret, apply and improve upon partner skills, (4) the top management's 
commitment to learning and (5) the capacity of the receptor to turn individual learning into collective learning ${ }^{[10]}$. Hamel ${ }^{[10]}$ further argues that learning becomes almost impossible if the skills gap between partners is too great.

The other critical element of ACAP is intensity of effort. This concept is proposed by $\mathrm{Kim}^{[14]}$. Intensity of effort is referred to as "the amount of energy expended by organizational members to solve problems" ${ }^{, 14]}$. Intensity of effort is achieved through organizational members focusing their considerable time and effort in learning how to solve problems before attempting to solve complex problems ${ }^{[14]}$. Zahra and George ${ }^{[33]}$ reconceptualize the concept by proposing ACAP to have four complementary dimensions capabilities that include: (1) knowledge acquisition, (2) knowledge assimilation, (3) knowledge transformation and (4) knowledge exploitation. Knowledge acquisition and assimilation capabilities form 'potential capacity', whereas knowledge transformation and knowledge exploitation capabilities form 'realized capacity' ${ }^{\text {[33] }}$.

A number of empirical studies on inter-firm KT have offered strong evidence on the relationship between ACAP and KT where: (1) capacity to learn is a strong indicator of knowledge acquisition from foreign partners $^{[16]}$, (2) ACAP is critical in the acquisition of capabilities in strategic alliance; where ACAP of the partners strongly depend on their prior experience in related technological fields ${ }^{[19]}$, (3) prior experience has a negative impact on ambiguity which impedes KT; where the greater/higher the levels of prior experience of knowledge seeker, the less ambiguous the knowledge to be transferred ${ }^{[27]}$, (4) a lack of ACAP is one of the barriers to $\mathrm{KT}^{[29]}$, (5) a higher ACAP in the local firms promotes more $\mathrm{KT}$ in new product development and manufacturing skills/techniques, (6) the recipient readiness has a positive impact on tacit knowledge acquisition $^{[32]}$ and (7) the local parent's receptivity is positively related to the amount of knowledge acquired from foreign partner $^{[31]}$.

H1: Absorptive capacity is positively related to degree of tacit and explicit knowledge in inter-firm technology transfer through IJVs.

Recipient collaborativeness and degree of technology transfer: Recipient Collaborativenss (RCOL) is mostly involved in inter-firm KT between partners in collaborative relationship such as strategic alliances and joint ventures. In intra-firm KT, firms are expected to encounter fewer problems when transferring knowledge and technology to their own subsidiaries and affiliates within the organizational boundaries. Strategic alliances provide an ideal platform for organizational learning especially through IJVs where partner firms can acquire, learn, create new knowledge and transfer knowledge between them ${ }^{[11]}$. Nonetheless, strategic alliances face a tradeoff between the opportunities for generating and sharing knowledge and the propensity that the partner may tend to become opportunistic $^{[11]}$. Building on the concept of interpartner learning developed by Hamel ${ }^{[10]}$, RCOL is defined as "the recipient firms' willingness to establish a mutually beneficial and collaborative relationship which requires the recipient firms' honest intention to create common benefits for both the supplier and recipient"[32]. Thus, learning in the collaborative relationship greatly depends on the partners' intent; whether the recipient partners' learning objective/intent is collaborative (complementary) or competitive ${ }^{[11]}$.

A stream of studies on inter-firm KT has established that a key determinant of interorganizational learning is partner's intent (collaborative vs. competitive intent $)^{[3,4,10,12,26]}$. Learning intent has always been referred to as: (1) an opportunity to learn and the desire and will of an organization to internalize a partner's skill and competencies ${ }^{[10]},(2)$ the desire and will of the partner firm to acquire the other firm's knowledge and skills ${ }^{[31]}$, and (3) the key condition for knowledge creation ${ }^{[20]}$. Past studies have contributed valuable theoretical arguments on partners' learning intent (competitive Vs collaborative intent) and its relationship with partners' collaborative attitudes in knowledge acquisition ${ }^{[10,12]}$. Most of the partners in strategic alliance consider their cooperative relationship as transitional devices where the primary objective is to learn and subsequently internalize their partners' skills and knowledge ${ }^{[10]}$.

A review of literature shows that very little empirical evidence is available with respect to the relationship between recipient collaborativeness and TTDEG. In a case study of nine international alliances, Hamel $^{[10]}$ found empirical evidence that partner's intent was a key determinant of inter-organizational learning in alliance. The only empirical evidence is provided by Yin and $\mathrm{Boa}^{[32]}$. In their study on the acquisition of tacit knowledge in China through IJVs, three aspects of recipient factors have been examined: RCOL, method comprehensiveness and recipient readiness. The result showed that among the recipient factors, RCOL was the most significant factor that had a positive impact on the tacit knowledge acquisition. Since learning in an alliance depends on the partner's intent, Simonin ${ }^{[26]}$ found learning intent was consistently emerged as the significant determinant of KT. 


\section{J. Social Sci., 5 (4): 423-430, 2009}

H2: Recipient collaborativeness is positively related to degree of tacit and explicit knowledge in inter- firm technology transfer through IJVs.

\section{MATERIALS AND METHODS}

Sample: The sample frame was taken from the number of IJV companies registered with the Registrar of Companies (ROC). As at 1st January 2008, the number of IJVs currently operating in Malaysia is 1038. Out of this, 850 IJVs are considered as active IJVs and 103 IJVs are either dormant or have ceased operation. Since the focus of this study is on inter-firm TT from foreign MNCs to local companies, 85 IJVs were further eliminated from the population frame because the IJVs that have operated more than 2 years and have at least $20 \%$ of foreign equity are eligible to participate in the survey. Therefore, based on the list provided by ROC, which is considered as the most official and original source of information on foreign investment in Malaysia, it was decided that all IJVs (850) be included in the survey. Data collection was conducted in the period from July 2008 to December 2008 using a selfadministered questionnaire. The questionnaires were mailed to 850 active JV companies as listed with ROC using a cover letter. After one month from the posting date the response was not encouraging. By mid July 2008 there were only 70 responses received from the respondents. Thus, in order to increase the response rate the researcher followed-up through numerous phone calls, e-mails, reminders via letters and personal visits to seek the respondents' cooperation in the survey. After intensive efforts were made, by mid November 2008 a total of 145 responses $(17.05 \%)$ were received. Based on literature review, the response rates for mailed questionnaires are usually not encouraging and low ${ }^{[25]}$. In the Malaysian context, however, a response rate of $15-25 \%$ is still being considered appropriate and acceptable ${ }^{[21,24]}$. From 145 responses only 128 questionnaires were usable and the balance were returned blank, returned incomplete, or replied but unable to participate in the study.

Instrument and measurement: The main research instrument in this study is the questionnaire. Building on the previous studies on KT and TT, the questionnaire adopts a multi-item scales which have been modified accordingly to suit the context of the study: inter-firm TT. Except for TTDEG, all the variables are measured using ten-point Likert Scale $(1-10=$ strongly agree $)$. For TTDEG, this variable is measured using ten-point Likert scale $(1=$ very low transfer to $10=$ substantial transfer). The ten-point
Likert scale was selected because (1) the wider distribution of scores around the mean provides more discriminating power, (2) it is easy to establish covariance between two variables with greater dispersion around their means, (3) it has been well established in academic and industry research and (4) from a model development perspective, a ten-point scale is more preferred ${ }^{[1]}$.

Dependent variable-Degree of Technology Transfer (TTDEG): This study adopts "a multi-dimensional operationalization approach" in measuring this construct $^{[7,9,15,16,32]}$. This study operationalizes TTDEG as the transfer of technological knowledge in terms of two dimensions: (1) Tacit knowledge (TCTDEG) in terms of new product/service development, managerial systems and practice, process designs and new marketing expertise and (2) Explicit knowledge (EXPDEG) in terms of manufacturing/service techniques/skills, promotion techniques/skills, distribution know-how and purchasing know-how. The respondents were asked to evaluate TTDEG from MNCs to local firms in terms of tacit and explicit dimensions of technological knowledge. The Cronbach Alphas for TCTK and EXPK were 0.96 and 0.97 respectively. The results of Cronbach Alpha was quite similar to that of Yin and $\mathrm{Bao}^{[32]}$.

\section{Independent variables:}

Absorptive Capacity (ACAP): Building on Lane et $a .^{[15]}$, this study captures ACAP's critical elements of ability to understand, assimilate and apply new external knowledge. In capturing these critical elements, this study adopts a multi-item scale previously used by the researchers ${ }^{[28,27]}$ to measure the constructs using 7 items with respect to statements on the academic background, technical capacity, educational programs, financial support for new ideas, overseas training opportunities and commitment in terms of personnel and resources (physical, financial and logistic) to JV. Following Cohen and Levinthal ${ }^{[6]}$ and Lane et al. ${ }^{[15]}$, this study also includes one (1) item to assess the local firm's ability to understand, assimilate and apply new technology transferred by the foreign parent firm.

Recipient Collaborativeness (RCOL): This study measures RCOL in terms of the local partner firms' learning intent and their collaborative attitudes by using a 5 items scale in terms of (1) the local partner's learning objective, (2) the local partner's desire, determination and will to learn from foreign partner, (3) the technology-recipient's willingness to allow foreign 


\section{J. Social Sci., 5 (4): 423-430, 2009}

partner to inspect and monitor the use of knowledge acquired from JV, (4) the local partner's commitment not to compete directly with the foreign partner in the future and (5) the local partner's commitment in sharing with the foreign partner the benefits of the critical knowledge acquired from the $\mathrm{JV}^{[10,26,32]}$.

\section{RESULTS}

Table 1 shows the descriptive data of all the variables (Mean values, Standard Deviations, Correlations). Table 2 presents the correlation matrix for all measured variables.

From Table 1, there are clearly some associations between independent variables. For all the variables, it was found that there was no multicollinearity problem; where the $\mathrm{T}$ values were ranged between 0.707-0.811 and the VIF values were between 1.238 and 1.414. Both Absorptive Capacity (ACAP) and Recipient Collaborativeness (RCOL) were significantly correlated with degree of tacit knowledge (TCTDEG) ( $\mathrm{p}<0.01)$. The correlation results also indicated that both ACAP and RCOL also had strong significant correlations with EXPDEG $(\mathrm{p}<0.01)$. Using the multiple regression analysis, the effects of ACAP and RCOL on two dimensions of degree of technology transfer (TCTDEG and EXPDEG) were estimated. As shown in Table 2 below, recipient collaborativeness as a critical component of technology recipient characteristics had significant effect on both degrees of tacit and explicit knowledge in inter-firm TT. The regression results indicated that recipient collaborativeness had a strong significant effect on both dimensions of technology transfer. This is evident by the results of the adjusted Rsquared (0.221 and 0.269) and F statistics (17.690 and 22.954). As the critical elements of technology recipient characteristics, recipient collaborativeness had a highly significant effect on both degrees of tacit and explicit knowledge $(\mathrm{p}<0.001)$. Therefore, H1 is supported thus indicating that the higher level of recipient collaborativeness, which is directly reflected on the recipient collaborative learning intent, contributes to a higher degree of tacit and explicit being transferred by the technology supplier partners in IJVs.

Surprisingly, although absorptive capacity has a strong theoretical foundation as highlighted by previous literature, nevertheless contrary to this study expectation, it has failed to provide any significant effect on both degrees of tacit and explicit knowledge ( $p>0.05)$.
Table 1: Descriptive statistics

\begin{tabular}{llllll}
\hline Variable & Mean & SD & 1 & 2 & 3 \\
\hline ACAP & 6.47 & 1.34 & 1.000 & & \\
RCOL & 5.75 & 1.67 & $0.541^{* *}$ & 1.000 & \\
TCTDEG & 6.56 & 1.66 & $0.329^{* *}$ & $0.460^{* *}$ & 1.000 \\
ACAP & 5.86 & 1.07 & 1.000 & & \\
RCOL & 5.84 & 1.70 & $0.541^{* *}$ & 1.000 & \\
EXPDEG & 6.60 & 1.64 & $0.313^{* *}$ & $0.517^{* *}$ & 1.000 \\
\hline $\mathrm{n}=128 ; *: \mathrm{p}<0.05 ; * *: \mathrm{p}<0.01$ & & &
\end{tabular}

Table 2: Results of group Regression Analysis ${ }^{\mathrm{a}}$

\begin{tabular}{lll}
\hline Variable & $\begin{array}{l}\text { Degree of tacit } \\
\text { knowledge }\end{array}$ & $\begin{array}{l}\text { Degree of explicit } \\
\text { knowledge }\end{array}$ \\
\hline (Constant) & $12.238^{* * *}$ & $14.597^{* * *}$ \\
Absorptive capacity & 0.1130 & 0.0470 \\
Recipient collaborativeness & $0.3990^{* * *}$ & $0.4910^{* * *}$ \\
$\mathrm{R}^{2}$ & 0.2210 & 0.2690 \\
Adjusted $\mathrm{R}^{2}$ & 0.2080 & 0.2570 \\
$\mathrm{~F}$ & $17.690^{* * *}$ & $22.954^{* * *}$ \\
\hline a: Cell entries are standardized coefficient estimates $(\mathrm{n}=128) ; *$ \\
$\mathrm{p}<0.05 ; * *$ : $<0.01 ; * * *: \mathrm{p}<0.001$
\end{tabular}

In this study, absorptive capacity as one of the critical elements of technology recipient characteristic has not really contributed to a higher degrees of tacit and explicit knowledge in inter-firm TT though the direction was correctly hypothesized. Thus, H2 is not supported. The results suggest that the presence of prior related knowledge about specific technology and intensity of effort, as critical components of absorptive capacity, do not necessarily help to increase degrees of tacit and explicit knowledge in IJVs. This unexpected outcome is probably due to the high degree of transparency (organizational and skills) which will undermine the learning (transfer) process, low organizational and individual learning commitment and low motivation to learn.

\section{DISCUSSION}

Based on the underlying integrated $\mathrm{KBV}$ and $\mathrm{OL}$ perspectives and since many of the inter-firm TT studies are theoritical and still under researched, this study has bridged the gaps in the literature by providing empirical evidence on the effects of two critical elements of technology recipient characteristics (ACAP and SPEC) on degree of inter-firm technology transfer and its two distinct dimensions namely: degree of tacit (TCTK) and explicit (EXPK) knowledge in IJVs using the Malaysia sample. From the regression results, the strong significant effects of RCOL on both degrees of tacit and explicit knowledge confirm the previous theory on the importance of recipient collaborativeness in facilitating TT through $\mathrm{JVs}^{[11]}$. The results suggest that the greater the degree of RCOL the higher the degree of tacit and explicit knowledge will be 
transferred by the foreign JV partners. In the cooperative venture such as JVs, the partner's learning intent is therefore crucial in encouraging openness and transparency of the transferring partner to share and transfer more technology ${ }^{[11]}$. Thus, if learning in JVs is being considered as competitive rather than collaborative, it restricts the flow of the required technology as the learning partner is treated as competitor $^{[10]}$. The results also suggest that collaborative learning, which is based on the underlying spirit of inter-partner collaboration, promotes knowledge sharing, mutual benefits and opportunities to extract potential synergy between partners in $\mathrm{JVs}^{[8]}$. Thus, with these incentives the transferring partner in JVs would have high motivation to share their technology in the collaborative environment and may not deliberately prevent the transfer of technology ${ }^{[11,12]}$. The results were in line with the previous studies which found statistical support for the effect of RCOL on degree of knowledge transfer ${ }^{[32]}$.

On the insignificance effects of absorptive capacity on both degrees of tacit and explicit knowledge (p>0.05), the first plausible argument is that transferring technological knowledge in strategic alliances and IJVs is an inter-partner organizational learning process; where it depends not only on prior related knowledge and intensity of effort of the learning partner but also 'other preconditions for receptivity' (absorptive capacity) of the learning partner such as sense of confidence, need to first to unlearn, size of skills gap with industry and ability to turn institutional learning to individual learning ${ }^{[10]}$. Moreover, the receptivity or absorptive capacity/capability of the learning partner (recipient) would not have significant effect on learning if (1) the transferring partner's (supplier) degree of transparency (organizational and skills) is high thus frustrating the learning (transfer) process, (2) there is low organizational and individual learning commitment and (3) low motivation to learn. Secondly, by looking at the results, there is a tendency that the effect of absorptive capacity in the study's models was superseded by the strong effect of recipient collaborativeness on both degrees of tacit and explicit knowledge thus 'overshadowed' the significant role of absorptive capacity. The results are consistent with Lane et al. ${ }^{[15]}$ where the effect of prior knowledge on knowledge learned from IJVs was found less significant in Hungarian IJVs.

\section{CONCLUSION}

Due to constraint of resources this study has mainly relied on responses obtained from the top management level of the JVs. Thus, the scope of respondents could have been broadened to include the middle and lower management levels in the JVs. Second, as the major limitation of many organization studies in Malaysia, the response rate in terms of the number of usable questionnaires, though sufficient, was not encouraging. Third, consistent with the literature, the nature of relationship between JV partners could have affected the results tremendously. The responses have a tendency to be biased should the respondents perceived that the JVs were competitive in nature rather than collaborative. The subjectivity of the nature of relationship thus is difficult to capture. Finally, the types of technologies under investigation were confined to tacit and explicit knowledge. This study can be replicated to cover other dimensions of value chain activities such as marketing, production or management technology.

Despite its limitations, this empirical study has responded to the need for statistical evidence that has typically been lacking in inter-firm TT literature. While this study focused on degree of inter-firm TT, future studies could be conducted to further examine the effects of technology recipient characteristics on level of innovation, competitiveness, productivity and technological capabilities of local firms. The above relationship could also be extended to cover other formal inter-firm TT agents such as FDIs and licensing. Secondly, the tacit and explicit dimensions of technology could also be extended to cover other dimensions of supply chain activities. It is worthwhile to find out the relationships and effects of technology recipient characteristics on other dimensions of tacit and explicit technology/knowledge of supply chain such as production, marketing, management and distribution. Thirdly, since JVs in developing countries have been perceived as unstable organization, future studies could empirically investigate the relationships and effects of degree of TT on learning outcomes, asymmetric bargaining power, stability of JV and equity ownership of the local firms. Finally, it is also worthwhile to investigate further the effects of several established moderating variables such as organizational culture, collaborative know-how, prior JV experience and learning capacity on the relationship as to provide further information on the boundary conditions of the relationship.

\section{REFERENCES}

1. Allen, D.R. and T.R. Rao, 2000. Analysis of Customer Satisfaction Data. 1st Edn., America Society for Quality, United States of America, ISBN: 0-8389-435-7, pp: 25-40. 
2. Barney, J.B., 1991. Firm resources and sustained competitive advantage. J. Manage., 17: 151-166. ISSN: 01492063

3. Baughn, C.C., J.G. Denekamp, J.H. Stevens and R.N. Osborn, 1997. Protecting intellectual capital in international alliances. J. World Bus., 32: 103117. ISSN: 10909516

4. Beamish, P.W. and I. Berdrow, 2003. Learning from international joint ventures-the unintended outcome. Long Range Plann., 36: 285-303. ISSN: 00246301

5. Cohen, W.M. and D.A. Levinthal, 1990. Absorptive capacity: A new perspective on learning and innovation. Admin. Sci. Q., 35: 128-152. ISSN: 00018392

6. Davenport, T.H. and L. Prusak, 2000. Working Knowledge: How Organizations Manage What They Know. Harvard Business School Press, Boston, MA. ISBN: 10: 1578513014.

7. Dhanaraj, C., M.A. Lyles, H.K. Steensma and L. Tihanyi, 2004. Managing tacit and explicit knowledge transfer in IJVs: The role of relational embeddedness and the impact on performance. J. Int. Bus. Stud., 35: 428-442. ISSN: 00472506

8. Geringer, J.M., 1991. Strategic determinants of partner selection criteria in international joint ventures. J. Int. Bus. Stud., 22: 41-62. ISSN: 00472505

9. Gupta, A.K. and V. Govindarajan, 2000. Knowledge flows within multinational corporations. Strat. Manage. J., 21: 473-96. DOI: 10.1002/(SICI)1097-0266(200004)21:4<473

10. Hamel, G., 1991. Competition for determinant and interpartner learning within international strategic alliances. Strateg. Manage. J., 12: 83-103. ISSN: 01432095

11. Inkpen, A.C., 2000. Learning through joint ventures: A framework of knowledge acquisition. J. Manage. Stud., 37: 1019-1043. DOI: 10: 1111/1467-6486.00215

12. Inkpen, A.C., 1998. Learning and knowledge acquisition through international strategic alliances, Acad. Manage. Execut., 12: 69-80. ISSN: 10795545

13. Inkpen, A.C. and M.M. Crossan, 1995. Believing is seeing: Joint ventures and organizational learning. J. Manage. Stud., 32: 596-618. ISSN: 00222380.

14. Kim, L., 1998. Crisis construction and organizational learning: Capability building in catching-up at Hyundai motor. Org. Sci., 9: 506-521. ISSN: 10477039

15. Lane, P.J., J.E. Salk and M.A. Lyles, 2001. Absorptive capacity, learning and performance in international joint ventures. Strat. Manage. J., 22: 1139-1161. ISSN: 01432095
16. Lyles, M.A. and J.E. Salk, 1996. Knowledge acquisition from foreign parents in international joint ventures: An empirical examination in the Hungarian. J. Int. Bus. Stud., 29: 154-174. ISSN: 00472506

17. Madanmohan, T.R., U. Kumar and V. Kumar, 2004. Import-led technological capability: A comparative analysis of Indian and Indonesian manufacturing firms. Technovation, 24: 979-993. DOI: 10.10116/S0166-4972(03)00030-0

18. Makhija, M.V. and U. Ganesh, 1997. The relationship between control and partner learningrelated joint ventures. Org. Sci., 8: 508-527. DOI: 1287/0rsc.8.5.508

19. Mowery, D.C., J.E. Oxley and B.S. Silverman, 1996. Strategic alliances and interfirm knowledge transfer. Strat. Manage. J., 17: 77-91. ISSN: 01432095

20. Nonaka, I. and H. Takeuchi, 1995. The Knowledge-Creating Company: How Japanese Companies Create the Dynamics of Innovation. Oxford University Press, New York, ISBN: 10: 0195092694, pp: 304.

21. Pak, Y. and Y. Park, 2004. A framework of knowledge transfer in cross-border joint ventures: An empirical test of the Korean context. Manage. Int. Rev., 44: 435-455. DOI: 10.1287/0RSC.5.1.14

22. Petaraf, M.A., 1993. The cornerstone of competitive advantage: A resourced-based view. Strateg. Manage. J., 14: 179-192.

23. Porter, M.E., 1985. Competitive Advantage: Creating and Sustaining Superior Performance. 1st Edn., Free Press, New York,1SBN: 10068484146.

24. Rozhan, O., Rahayu and Rashidah 2001. Great expectation: CEO's perception of the performance gap of the HRM functions in the Malaysian manufacturing sector. Person. Rev., 30: 61-80. DOI: $10.1108 / 00483480145$

25. Sekaran, U., 2003. Research Methods for Business, Fourth Eds. John Wiley and Sons, Inc. ISBN: 0471-20366-1.

26. Simonin, B.L., 2004. An empirical investigation of the process of knowledge transfer in international strategic alliances. J. Int. Bus. Stud., 35: 407-27. DOI: 1057/palgrave.jibs.840091

27. Simonin, B.L., 1999. Ambiguity and the process of knowledge transfer in strategic alliances. Strat. Manage. J., 20: 595-623. DOI: 10.1002/(sici)10970266 (199907)20:7<595

28. Szulanski, G., 2003. Sticky Knowledge: Barriers to Knowing in the Firm. SAGE Publications, London, ISBN: 10: 0761961437. 
29. Szulanski, G., 1996. Exploring internal stickiness: impediments to the transfer of best practice within the firm. Strat. Manage. J., 17: 27-43. ISSN: 01432095

30. Anh, P.T.T., C. Baughn, N.T.M. Hang and K. Neupet, 2006. Knowledge acquisition from foreign parents in international joint ventures: An empirical study in Vietnam. Int. Bus. Rev., 15: 463-487. DOI: 10.1016/j.ibusrev.2006.05.004

31. Tsang, E.W.K., D.N. Tri and M.K. Erramilli, 2004. Knowledge acquisition and performance of international joint ventures in the transition economy of Vietnam. J. Int. Market., 12: 82-103. DOI: 10.1509/jimk.12.2.82.32901
32. Yin, E. and Y. Bao, 2006. The acquisition of tacit knowledge in China: An empirical analysis of the supplier-side individual level and recipient-side Factors. Manage. Int. Rev., 46: 327-348. ISSN: 1081432651

33. Zahra, S.A. and G. George, 2002. Absorptive capacity: A review reconceptualization and extension. Acad. Manage. Rev., 27: 185-203. ISSN: 03637425 